DOI: 10.20472/IAC.2017.33.021

KIM HEYES

Manchester Metropolitan University, United Kingdom

MARCIN WOZNIAK

Manchester Metropolitan University, United Kingdom

\title{
'THIS IS WHAT HAPPENS WHEN A TUTOR BELIEVES IN YOU' - SETTING UP A STUDENT JOURNAL TO FACILITATE COMMUNITY COHESION.
}

\begin{abstract}
:
This pilot project sought to identify whether creating a community through setting up a student-run academic journal would increase self-efficacy and academic achievement. The project was set up in a small university campus of less than 2000 students, with a view to extending the project to the whole university population of 38,000 students if successful.

Participants were recruited through posters on the campus and through a recruitment desk at the entrance to the student recreation area (opportunity sample). At the recruitment desk, a random sample of people were asked to fill out the questionnaire, and this questionnaire was also given to the participants at the initial meeting. A total of 30 questionnaires were completed.

The participants then went through the process of creating a student journal, and were assigned roles by the Editor. Once the journal had been published, the participants were asked to complete the questionnaire again. Comparisons were made between the two sets of results to determine the outcome. Once the results of the academic year had been released, the academic marks were also taken into account in comparison with the general population of the immediate university campus. Although the sample size for the second questionnaire was small, it was clear that the participants felt that they were part of a community after the project than before, with a stronger sense of belonging. They were also more confident in their academic abilities and their future employability. All students involved achieved a 2:1 degree classification or higher, with $90 \%$ of the overall journal team achieving a 1st class honours degree classification. The Editor also won an award for academic excellence due to her involvement with the creation of the journal.
\end{abstract}

\section{Keywords:}

Student achievement, self-efficacy, employability, academic achievement, student journal

JEL Classification: 129 


\section{Introduction}

The closure of small satellite campuses around the UK (and beyond) are becoming more and more frequent. Manchester Metropolitan University Cheshire campus (ManMet Cheshire) is one that has recently been affected. This paper is not however a political statement about the state of the university system, but focuses on the effect on the existing students. The threat of mass staff redundancies (whether or not they actually happen) brings an air of disillusionment to everyone concerned, which regardless of how much lecturers, administrative and site staff try to minimise the impact, will still be felt by the student cohort. Heller and Cassady (2015) found that environmental factors can be significant predictors of academic achievement, which builds upon Johnson et al's (2007) study which shows that community cohesion within an institution is essential for students to excel.

The Student Academic Innovation Journal was borne out of a concern that community cohesion (or spirit) at ManMet Cheshire was struggling since the announcement of the closure took place on the $24^{\text {th }}$ June 2016 (also known as the day the UK voted for Brexit), and there was to be no further intake of students. This meant that year on year, the student cohort would drastically diminish. Community cohesion, peer support and academic achievement would therefore become more difficult and the learning experience would be poor. The aim of producing a journal was to help target some of those important issues.

Feedback from academic staff gathered by Student Experience Tutors at Cheshire Campus suggest that student lack of engagement with academic journals have a negative impact on academic performance of students. The project will also act as a cooperative inquiry where we will aim to find out what issues student may be facing when accessing or reading academic journals, and explore ideas on how these issues could be solved.

The skills learnt to produce a journal and to collaborate as a team, are skills that can be easily transferred to the job market. Writing essays is generally a solitary experience, and most employers look for the ability to be able to work with others as well as being productive whilst working alone. Giving the students the opportunity to learn these skills by producing something practical that they are able to showcase not only instils this work ethic, but can boost self-esteem when they are proud of the outcome. This can however, also prove to be a negative experience if the group are not able to work well together and do not produce something that is off a high standard (Crabtree and Haslam, 2010). Even when a negative experience is had, there are still lessons to be learnt. This can be about learning how to choose people to work with and that sometimes it is difficult to work as a group (this is particularly relevant to the workplace, as often there is no choice about who you work alongside).

It has been shown that through involving students in building their own output for their academic work, self-efficacy and academic skill levels increase considerably (Coffield et al. 2004). By putting together a journal, the students will gain workplace skills around 
the process of this, including how to peer review work, how to make decisions as an editorial board, how to create an effective layout and how to promote the journal (amongst others). Students will work in partnership with other students and staff to achieve the outcomes.

Research questions:

1. Does producing a journal help to create a sense of cohesion within the student community?

2. Does the community cohesion help to improve academic outcomes?

The research was informed by McMillan and Chavis' (1986) theory of sense of community, and using their models of community cohesion along with the sense of community scale (SCS), a questionnaire was formed. Alongside this, the practice of action inquiry (Torbert, 2006) will allow for hearing individual student voices through students involvement in the process of cooperative inquiry (this will be reported in a later paper). Student input will support the design of the SAI Journal and contribute to the development of further recommendation for good practice in engaging students with reading academic journals and publishing their work.

The project aims to promote innovation and collaborative working by setting up a journal for all student levels across the ManMet Cheshire campus, with a view to rolling it out to the whole university after this pilot project. It has been shown that through involving students in building their own output for their academic work, self-efficacy and academic skill levels increase considerably (Coffield et al. 2004). By putting together a journal, the students will gain workplace skills around the process of this, including how to peer review work, how to make decisions as an editorial board, how to create an effective layout and how to promote the journal (amongst others). Students will work in partnership with other students and staff to achieve the outcomes.

\section{Peer Support}

Through boosting the self-esteem of the students and showing pride in their academic outputs, lecturers often suggest that students should go on to further study and/or should publish their work. However, students do not know how to go about publishing, and are often too afraid to try. There are also students that feel that they do not have the academic ability to achieve the top grades, and they may feel as though they do not know how to access the tools to improve. Part of the research is about de-mystifying so of these areas. Publishing an article shouldn't be scary, but something that is possible, and those that feel as though they are never going to get the top grades may need peer support or a reading or writing workshop. You may be thinking here that these kinds of workshops are always available at universities! However, often they are poorly attended because of the time of year that they are offered (weeks off of timetable/ reading weeks), and the student may feel uncomfortable attending as they may be seen by their peers as unintelligent. 
Supporting students can take many different guises. There are those who have recently moved away from home, who have difficulty adjusting to life without close family members, or those who need constant reassurance about their intelligence all the way up until they graduate. There are many other types of support required by students, and this requires significant input by lecturers. Often this input is limited due to sheer numbers of students or time commitments to research. Many may get this support through relationships gained in their first few weeks, however, for those who may struggle with peer relationships, or who do not live in student accommodation, it is important that they find a way to build a relationship with their peers. By encouraging the students to participate in peer assessment projects they could increase their selfefficacy and ultimately improve their performance over the time over their undergraduate degree. Smith et al. (2002) found that by using peer assessment and teaching the students to assess each other, that there was also a significant increase in confidence and academic development.

\section{Self-efficacy}

As Coffield et al. (2004) state in their research, learning achievements generally come from the ownership that students take of their own work, rather than directly from the change in approach around learning styles. Therefore, by encouraging students to take responsibility for what they produce, what they learn through engagement of the activity is more important that the activity itself.

Much research has been undertaken on how increasing self-efficacy can help students to focus on their studies and build support networks since Bandura's formative works (Bandura, 1977). Increasing self-efficacy has been shown to positively influence behaviour, for example those who become involved in showcasing their own work will then take ownership of the quality of this, thus working harder to achieve a better outcome.

'Self-efficacy research is well established within the educational sector and a wealth of research findings indicate that self-efficacy correlates with achievement outcomes' (Kitching et al., 2011:11). Students can be more motivated to succeed if their levels of self-efficacy are high and the feelings of achievement can spur them on to achieve in all areas of their studies. Therefore, increasing levels of self-efficacy can greatly increase the outcomes of the students undergraduate degree, possibly increasing the mark that they would have gained otherwise.

Similarly to Coffield et al. (2004), Billington (1997) found that undergraduate students benefit from a range of learning styles. Those who were struggling with essays tended to do better when asked to complete a poster project for example. Billington (1997) believed that universities could be failing students by only using one form of assessment and that by creating other opportunities for assessment, discrimination could be eliminated. This would lead to students from all backgrounds having an equal chance at success in their undergraduate degrees. Deonandan et al. (2013) also believed that 
the success of students could be hindered by the pedagogical approach to teaching. By getting students involved in their own learning experience and also helping their peers, they will gain more from the experience than a typical lecture (Brew, 1999, Elton, 2001).

The benefits of a peer review system is to get students used to the way other academic journals work, and to remove the stigma of the academic journal or article as something alien to a student. Student involvement in the process may help further support our understanding on how to engage interest of other students in taking part in projects that can broaden their employability perspectives (Harland et al, 2016). Often post-graduate (and sometimes under-graduate) students are told to publish their work but have no idea how to do it, and the experience of submitting articles is daunting. By getting students to participate in this process from undergraduate level, hopefully the process will be less daunting, and will encourage more students to put their work forward.

\section{The Journal Process}

The idea of the journal came from an enthusiastic student. She became the Editor-inChief, and was an excellent advocate for creating a community and helping her peers. We won a bid for a small amount of funding ( $£ 3880)$ from the Manchester Metropolitan Centre of Learning and Teaching Scholarship of Learning and Teaching Research Grant (CELT SoTL), and put our research into action.

The project began in September 2016, as the students returned for the beginning of term. We advertised for volunteers and put out a call for papers throughout the Cheshire campus. Staff were also asked to promote the journal within their lectures.

There were several articles submitted, and through peer review, these were narrowed down to a final eight, and a selection of students who had submitted a paper/ article were invited to review other articles that were submitted. The paper edition of the journal was produced containing articles from courses across all disciplines: Abuse Studies, Psychology, Creative Writing, Sociology, Sport and Exercise Science, and English.

A website was also produced, with online journal editions. This was to make the journal highly accessible to all students, even those who study from a distance. Going forward the website will be particularly beneficial to students who may wish to engage with creating articles in other mediums, such as images or film. It is important to acknowledge the openness of the range of formats for the articles to ensure that students engaged in all disciplines feel able to get involved. Articles based on student experience of their course, campus, MMU may have a further positive impact on other students engagement, through showcasing the range of opportunities and activities available to students.

The nature of producing a journal means that there will be opportunities for a core group of people to sit on the governing board, and then opportunities for volunteers to give as much/ little time as they wish to help with the production and peer reviews. This also 
means that students with family or caring commitments will not miss out due to time constraints.

However, we realised that we could not just ask students to produce something that they had never done before, so as post-graduate students ourselves (Kim is a PhD final year student and Abuse Studies Lecturer and Marcin is a Masters student and Student Experience Tutor) we made ourselves available to help with the running of the first publications. Marcin also created reading and writing workshops to help those who wanted to publish but didn't have the confidence in their own skills.

\section{SAl Journal - An agent for engagement and belonging on campus.}

There are already some projects for disseminating work within Manchester Metropolitan University, such as the open access e-space for academics, and the ManMet Psychology journal, however the project aimed to give students something that they can own, rather than feel that they have to compete with existing academics works. To be able to produce a real journal also added to the sense of achievement for those involved in the production. Articles based on student experience of their course, campus and ManMet, highlight the range of opportunities and activities available to students, and may have a further positive impact on student engagement with activities available on campus. Baron and Corbin (2012:763) describe an engaged student as a 'student who has a positive, fulfilling and work-related state of mind that is characterised by vigour, dedication and absorption and who views him or herself as belonging to, and an active participant in, his or her learning communities.'

Therefore, engagement needs to be considered in relation to the sense of belonging developed within learning communities on the course, social groups on campus and feelings of belonging to the institution itself. Thomas (2012) suggests that belonging in Higher Education (HE) is closely aligned with academic and social engagement and is central to student retention and success, therefore showcasing students' academic work, projects and achievements, alongside affording a space to interact with others has a potential for the enhancement of student belonging within the institution.

The nature of producing a journal means that there will be opportunities for a core group of people to sit on the governing board; opportunities for volunteers to give as much/ little time as they wish to help with the production and peer reviews, allowing students with family or caring commitments not to miss out due to time constraints.

\section{Engaging students with the 'academic process'}

One could argue that academia is just for the 'academic' students. As part of the project, we wanted to ensure that students across all abilities were engaged, and to offer opportunities for all students to participate in the SAI Journal aiming to enhance student experience. 
Current Higher Education climate is increasingly directed towards marketization, through the introduction of tuition fees, internalisation and increasing pressure to maximise efficiency through larger cohorts (Collini, 2011). As a result, universities often take on students with a range of qualifications, increase the number of international students, or mature students that have been out of education for some time. Such diversity of student from different education backgrounds make it impossible to make sure that all students are on the same level of preparation for university life. HEls need to consider if their students can relate to the institutional culture to allow the development of the sense of belonging (Thomas, 2002).

From the researchers' experience, both academic and support, there is a high percentage of students within HE that have not yet grasped basic academic skills such as structuring an essay. Often it is left to the student to learn the skills, by attending generic academic study skills extracurricular courses, but the engagement depends on the students themselves. Assumption about HE students as independent, and having appropriate skills to take their own responsibility for, can lead to shifting responsibility from the university to the student, and lead to dismissing of the different needs (Reay, 2003). Embedding study skills within the course by linking necessary skills to the assignment offers a solution, but such an approach can have specific constraints on already full timetables and resourcing.

Taras (2003) found that the expectation of higher grades from students came from the time and effort they felt that they had put into their work, not from how they perceived their own ability. It also seems that the increased fees make students believe that they are buying into a 'sure thing', and expectations are that they will be spoon fed by their lecturers in order to get a good grade (Whitelock et al., 2014). The increased pressure on the lecturer to get good grades from their students is also high, as these are then published for potential students, which clearly has an impact on levels of people signing up for the course in future years.

Lecturers at ManMet Cheshire were realising that even though academic skill workshops were on offer, only a fraction of the students actually seek this help. Those that do benefit greatly from such support. One student in particular was worried about her dyslexia so sought help after receiving $42 \%$ on her first paper. One year later, she received a result of $85 \%$, the highest mark in the class, a phenomenal achievement. The point being that she worked hard to achieve the mark, took note of the feedback made on her essays, and took advantage of all of the extra support offered. Other students do not put this amount of effort in, and are disappointed (and are often angry at the lecturer) that they have not improved their marks in the same way.

However, not all students find this type of engagement easy to access. Drawing upon the idea that students learn by doing, a collaboration of students and staff emerged to create a project that engages students with the concept of academic work, skills needed to create quality academic work and the showcasing of exceptional work. Therefore, development of reading and writing skills, engagement with reading of academic journals and providing the space to write became an integral part of shaping of the SAI 
Journal. 'Reading and Writing Retreats' were set up to help students engage with the reading and writing process and create supportive learning community (Engstrom and Tinto, 2008).

\section{Reading Retreats}

Reading retreats were adapted from 'Structured Reading Groups' (Macpherson- Parrott and Cherry, 2011) and aim at engaging students with critical reading of academic journals, developing their depth of understanding and helping students to participate in active discussions about read materials, through critically analysing and summarising gathered information. Within the workshops, students take on various roles within the reading process:

- Discussion Leaders develop possible discussion questions to aid understanding around the main points of the assigned reading;

- Passage Masters locate a few important passages within an article;

- Creative Connectors make connections to other important ideas explored in the session, and to other cultural, social, political, and economic ideas;

- Devil's Advocates challenge the ideas in the article by developing a list of critical, thoughtful questions and arguments that might be raised by critics of the authors or by those with different points of view;

- Reporters take notes during the discussion and summarize its main points. After the discussion, the reporter writes a brief summary of the group discussion.

(Heyes and Wozniak, 2017)

The purpose of the roles is to give students responsibility within a group task, to aid engagement with deep reading, which may lead to better understanding of the concepts. The energy created through the student interaction within the session, makes the process more fun and engaging. Such learning communities allow for a safe place where students can ask questions and learn from one another. This therefore, supports community cohesion and the development of skills needed within academic studies, which will be transferable to future employment.

\section{Writing Retreats}

Academic writing amongst other study skills play a vital role in student academic engagement, performance and retention. Students often manage their coursework by leaving insufficient time to seek support, which can affect the outcomes. Not having enough time to complete the assignment and lack of knowledge of available support can then lead to student disengagement. Zimmerman (2002) identifies that for students to enhance self-satisfaction and motivation in improving their methods of learning, the learner must set goals and self-reflect on their increasing effectiveness. He further suggests that students who set specific and realistic goals for themselves display higher achievement and increased self-efficacy. According to Kitching et al. (2011) students 
with belief in their own capabilities are more likely to be motivated to succeed in difficult situations. The Structured Writing Retreats somehow seemed like a 'new companion' to the study skills workshops, space for students to engage with the writing process in a good time before the assignment is due. This then also allows time for the development of ideas, and time for editing and accessing additional support.

The Writing Retreat was developed from Writing Retreat Facilitator Guide (Murray and Newton, 2009). It include an individual time to set writing goals achievable within halfhour writing slots or within the full session and make a plan of how the content will be covered. Participants needed to consider what is achievable in the designated time, share their writing goals with others, explain their writing project, goals and the reasoning behind it, before discussing with others if the goals are achievable. Throughout the retreat, participants continue to reflect on whether they have achieved their goals, whether they should adjust their goals in relation to what they have accomplished, and are encouraged to learn from each other. This approach can help students to develop an approach to writing that is engaging and provide realistic timescales and organisation.

Students' feedback on the activity highlighted the benefit of a social aspect of the retreat, having a critical friend and a sense that you are not alone in this situation. Beachboard et al. (2011) argue that student-learning communities allow for the development of belonging and relatedness, which leads to student motivation, confidence and interest in learning.

During the retreats, students have an opportunity to reflect on their experiences of academic reading and writing process, discuss them with the group to find solutions to the problems and learn effective ways of working, to enhance performance and seek further support if necessary.

The reading and writing retreats will be rolled out alongside the journal in the other ManMet campuses in due course.

\section{Participants}

Recruitment drives for participants have included leaflets, word of mouth, posters and a stand in the 'student zone' (a prominent area in the cafeteria). Thirty students filled out the initial questionnaire, including the participants of the project.

There were 14 participants involved in the project of creating the journal. They were aged between 19 and 60 with the mode being 20 years old and a standard deviation of 9.8. The majority are female (9), however the time spent working on the journal was equally split between the males and females. The majority were English (10), although participants were from Poland, Germany, Scotland and Ireland too. As the project was several months in duration, participants were given the freedom to participate in the creation of the journal as and when they could, hence not all participants were available 
to complete the final questionnaire. Most of the students (12) were final year undergraduates.

The participants filled in a consent form at the beginning of the project. The nature of the creation of the journal meant that all participants of the project agreed to their names being made public, although their answers to the questionnaires were anonymised. Ethical approval was granted through the Manchester Metropolitan University ethics board and ethical standards were upheld as per British Psychological Society (BPS) guidelines.

\section{Method}

A short questionnaire of 13 questions was given to an opportunity sample of 16 members of the general student population and the 14 participants of the student journal project. Ten of the project participants repeated the questionnaire after the publication of the journal. The questions were designed to analyse feelings of confidence, sense of belonging, sense of community, academic ability and confidence in future employability. The final year students academic performance was also taken into consideration against the general population of the Cheshire campus. As the samples were small, it was not appropriate to infer statistical significance, however, the data is robust enough to develop a larger scale project.

By applying a mixture of how the ManMet student community feel through a questionnaire on community cohesion and work ethics of those involved in the project, we can measure how successful the project is answering our research questions. 


\section{Results}

Figure 1. Questionnaire responses from the initial sample of 30 students (October 2016).

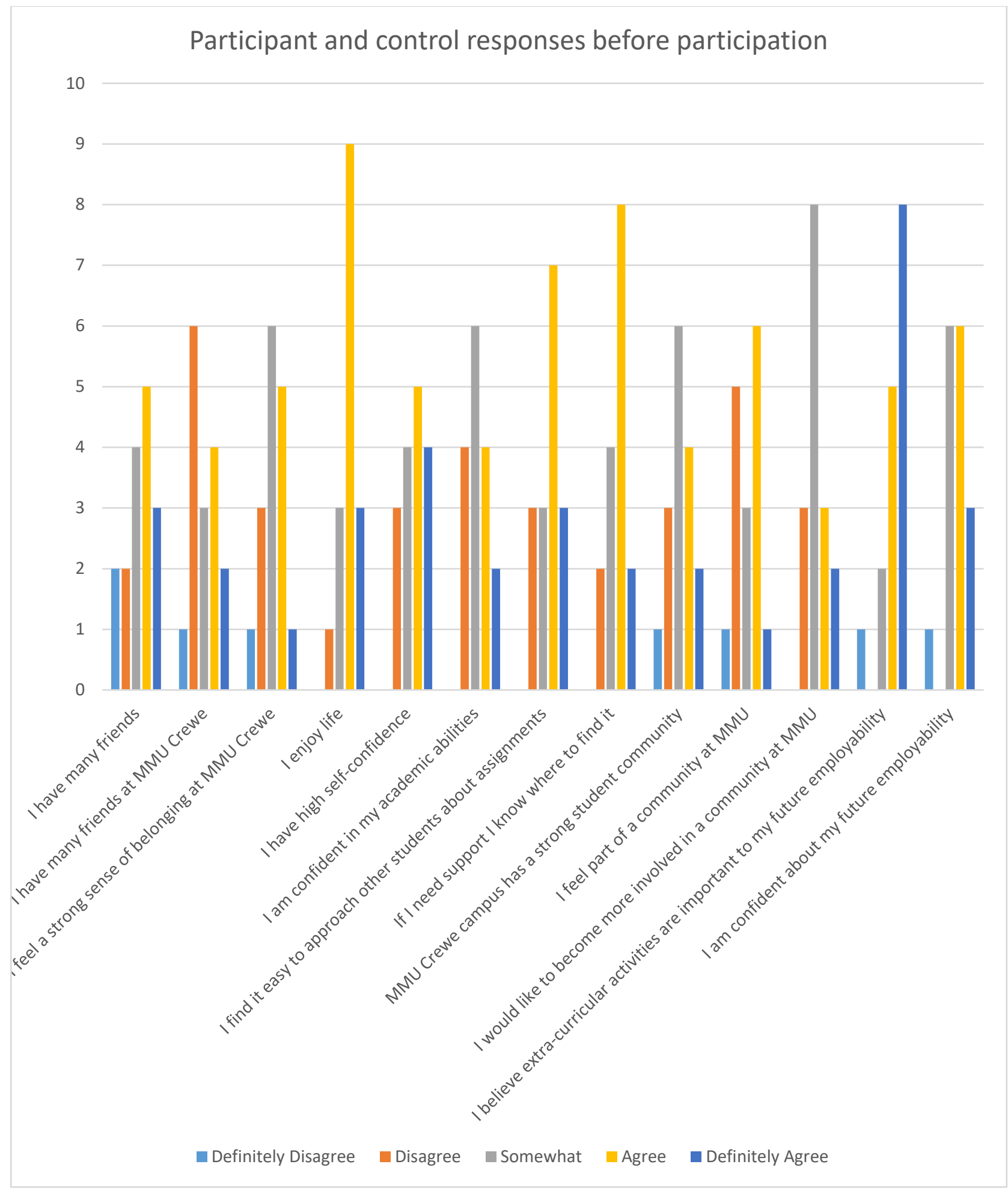


Figure 2. The questionnaire responses from the 10 project participants (February 2017).

\section{Participant responses after participation}

8

7

5

4
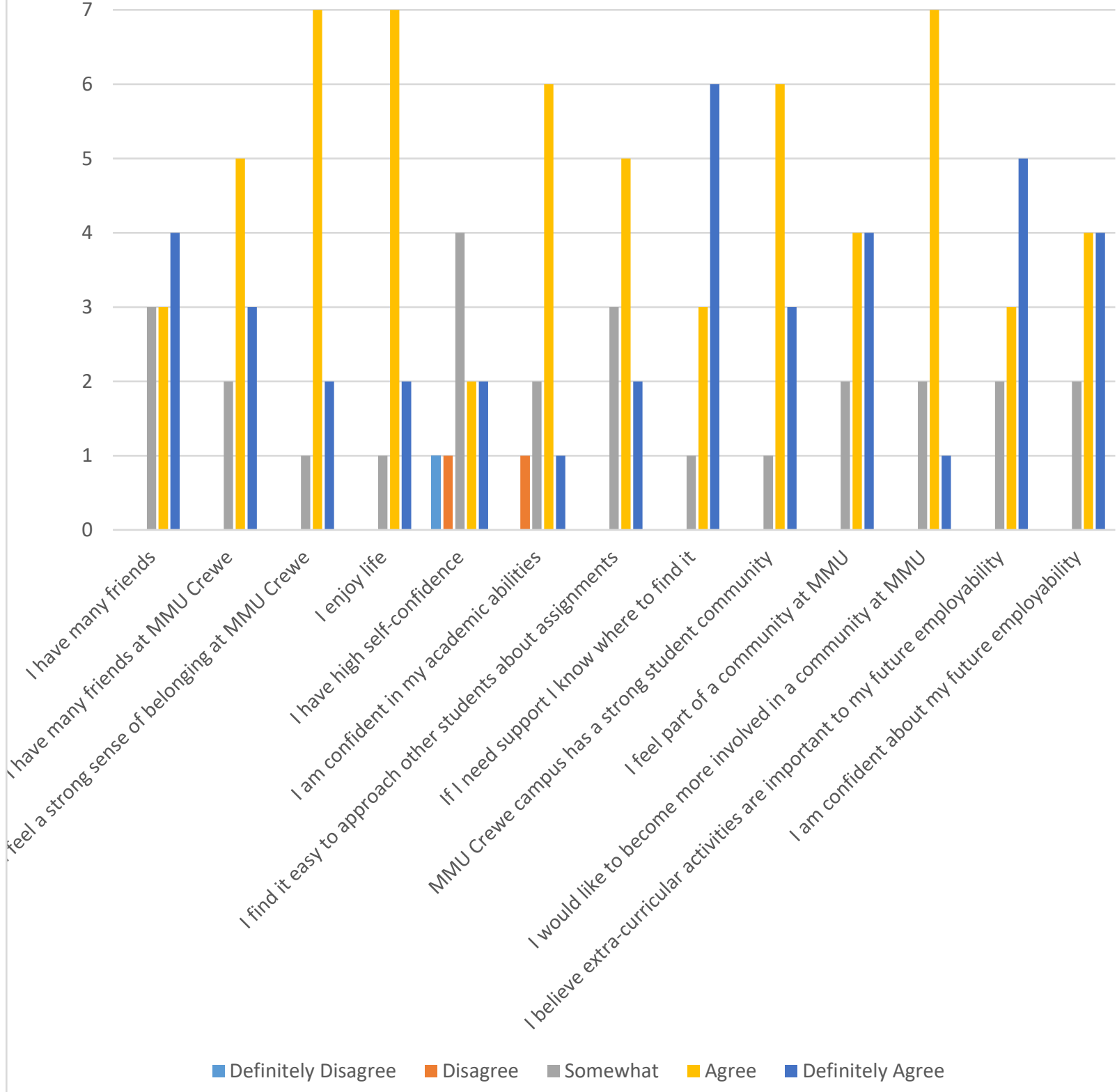
Figure 3. Sense of belonging.

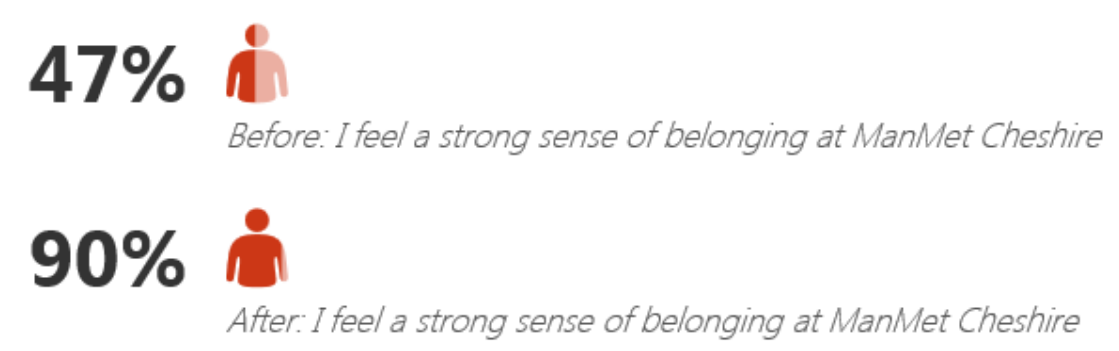

Figure 4. Student community.

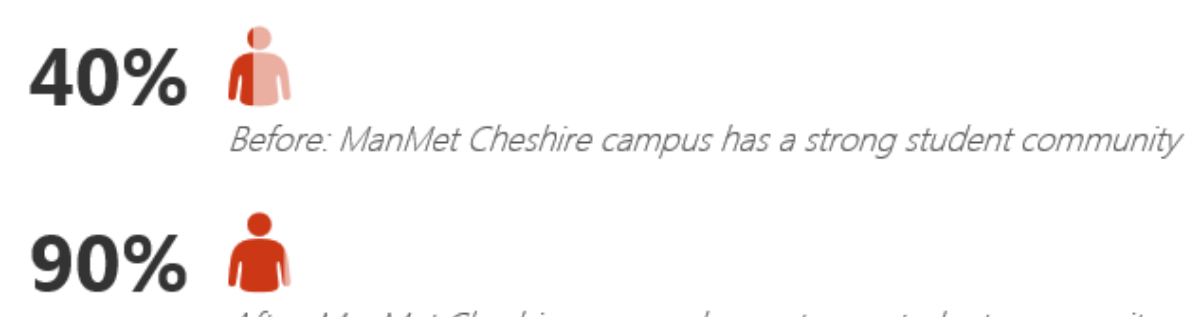

After: ManMet Cheshire campus has a strong student community

Figure 5. Feeling part of a community.

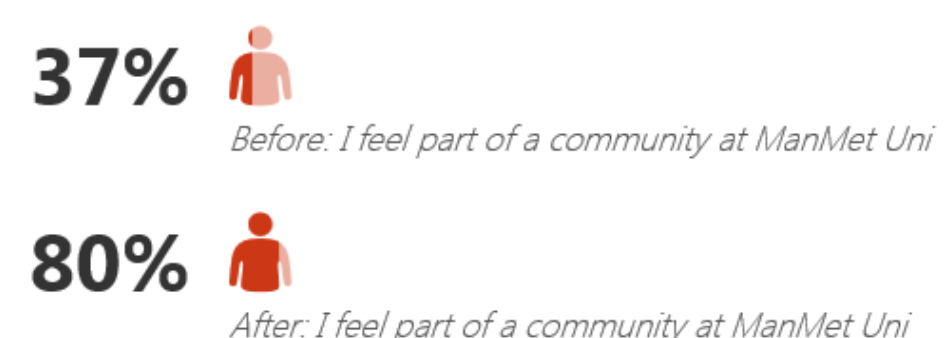

After: I feel part of a community at ManMet Uni

Figure 6. Confidence in employability.

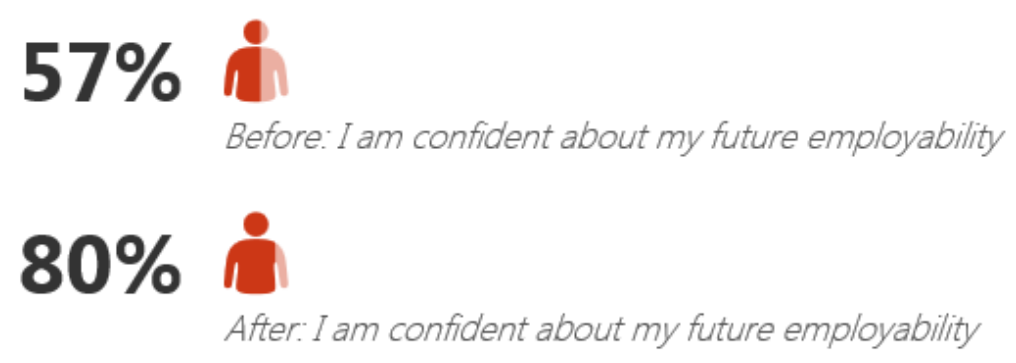


Four of the thirty participants in the first questionnaire reported that they strongly disagreed, or disagreed with the statement 'I feel a strong sense of belonging at the Manchester Metropolitan Cheshire campus', with the majority of the sample population stating that they were 'somewhat' in agreement with this statement. After the project, the majority of the participants agreed or strongly agreed with this statement, and none of the participants disagreed.

Overall satisfaction levels with the campus community rose significantly, and $90 \%$ reported feeling a strong sense of belonging, compared to just $47 \%$ before the project. $80 \%$ felt that they were now part of a community in comparison to just $37 \%$ at the beginning of the project. 53\% of the participants were already confident in their academic abilities, which went down to $40 \%$ after the project. However, the timings of the questionnaires may have had more of a bearing on this than the project itself (the start of term vs mid-year).

All of the participants felt that community engagement and extra-curricular activities were important to their future employability.

$86 \%$ of the level 6 participants completed their undergraduate degree with a $1^{\text {st }}$ classification (12 out of the 14 participants), compared to $20 \%$ of the Cheshire Campus as a whole (138 out of 676 ). $75 \%$ of these students were first generation students (their parents did not gain university level qualifications).

\section{Discussion}

The research aimed to answer the questions:

1. Does producing a journal help to create a sense of cohesion within the student community?

2. Does the community cohesion help to improve academic outcomes?

Through understanding the role of self-efficacy and sense of community and how a project such as putting together a student journal can affect these, we can try to find what effect this has had on academic achievement. From the difference between the first and second questionnaires it has been possible to infer that the journal did help to create a sense of community cohesion, and therefore led to improved academic outcomes.

Self-efficacy, sense of community and academic achievement were all shown to have greatly improved as a result of the project. The small opportunity sample means that there could be issues with relating the results to the student population as a whole, however, it is important to recognise that there was a high level of success within this sample which should not be ignored. A further qualitative study will analyse these areas further, and help the researchers to create a larger scale project. 


\section{Self-efficacy}

The self-efficacy questions didn't show much improvement, and in fact, several participants expressed that they were less confident in their abilities after the project. The majority $(75 \%)$ of the participants were students at level 6 , most of whom had recently received marks back for their first assignments and were thinking about the level of work that they still had to complete before the end of March (the second questionnaires were completed on February $14^{\text {th }}$ ). The stress that the students were under at this point could go some way towards explaining the significant decrease in sense of academic ability and lack of an increase in self-efficacy.

\section{Sense of Community}

The positive outcomes around a sense of community could be attributed to the project as it brought together students from various disciplines that would not usually come together as a group. Two out of three questions on community rose significantly in satisfaction levels, and through preliminary analysis of qualitative interviews, it seems as though the student journal did create a strong community bond between the cohort.

Sense of community was significantly stronger after the project, with sense of belonging to the campus, feeling part of a community and feeling that the campus had a strong community all increasing by at least $43 \%$. The group worked well together and held regular meetings which could have contributed to this sense of community. The second questionnaire was filled in after the journal launch party where all of the participants were celebrated at an awards ceremony. This may have helped to boost feelings of achievement and camaraderie, which could have been why the impact was so high in the second questionnaire.

\section{Academic Achievement}

The level of academic achievement by the project participants was way above expectations. $86 \%$ of the project student cohort achieved a $1^{\text {st }}$ class honours degree, in comparison $20 \%$ of all Cheshire Campus students in 2017. This outcome could be attributed to the experience; however, it is also reasonable to assume that the students would have gained excellent marks regardless of the project, and that perhaps their academic ability is what drew them to participating in the project in the first place.

The researchers of the study were also participants, and this can create a researcher bias. However, the process of producing a journal was a learning journey for all concerned! Studying a small campus is relatively easy, as the numbers that wish to participate are small. Although this means that some of the inferences made are not able to be tested with parametric tests, and the valid significance cannot therefore exist, small studies such as this must not be discounted. As academics, we should be mindful that the changing political landscape of universities, and the impact of university 
closures will have a negative impact on students. If we could replicate the results of this study to help even one more student cohort, then we would be very happy indeed.

\section{Outcomes and further studies}

The journal itself was very successful, however to be able to test the significance of the academic achievement and increase in sense of community and self-efficacy, we would need a larger sample size, which we hope to do in 2018. This was a mixed methods study, and the qualitative analysis will be completed later in 2017.

The aim for the students was for the journal to feel like one of the professional publications that can be found in our university libraries, but the process that the students went through from start to finish meant that the final product was so much more. All of the level six students reported that they had put the journal on their CV in order to gain future employment or to be accepted into further education programmes. Three of the students were accepted and presented at the British Conference of Undergraduate researchers, and the final degree classification results of all of the students far exceeded our expectations.

The researchers also had a good working relationship with the student cohort, and wish to take the student journal forward, increasing its size and reach within ManMet. The next stage of the research will be a longer term study to explore the employability of the students as a result of their involvement in academic community peer support.

The SAI journal website can be found at: www.saijournal.com.

\section{References}

Bandura, A. (1977). Self-efficacy: Toward a unifying theory of behavioral change. Psychological Review, $84,191-215$.

Bandura, A. (2012) On the Functional Properties of Perceived Self-Efficacy Revisited Journal of Management 38, 9-44

Baron, P. and Corbin, L. (2012) 'Student engagement: rhetoric and reality', Higher Education Research \& Development, 31:6, 759-772

Beachboard, M., Beachboard, J., Li, W. and Adkinson, S. (2011) 'Cohorts and relatedness: selfdetermination theory as an explanation of how learning communities affect educational outcomes'. Research in Higher Education. 52, 853-74.

Coffield, F., Moseley, D., Hall, E., Ecclestone, K. (2004) Learning styles and pedagogy in post-16 learning. Learning and Skills Research Centre

Collini, S. (2012) What Are Universities For? Harmondsworth: Penguin.

Engstrom, C., \& Tinto, V. (2008). Access without support is not opportunity. Change, 40(1), 46-51. 
Crabtree, J.W, \& Haslam, S.A. (2010). Mental Health Support Groups, Stigma, Self-Esteem: Positive and Negative Implications of Group Identification Journal of Social Issues vol 66:3, 553-569

Harland, T., Wald, N. and Randhawa, H. (2016) 'Student peer review: Enhancing formative feedback with a rebuttal.'Assessment \& Evaluation in Higher Education, 1-11.

Heller, M. L. and Cassady, J. C. (2015) 'Predicting community college and university student success.' Journal of College Student Retention: Research, Theory \& Practice

Heyes, K. and Wozniak, M. (2017) 'The SAI Journal Project Overview' Student Academic Innovation Journal, 1, 8-10.

Johnson, D. R., Soldner, M., Leonard, J. B., \& Patty, A. (2007). Examining sense of belonging amongfirstyear undergraduates from different racial/ ethnic groups. Journal of College Student Development, 48(5), 525-542

Kitching, J., Cassidy, S., Eachus, P., and Hogg, P (2011) Creating and Validating Self-Efficacy Scales for Students The American Society of Radiologic Technologists 83:1, 10-19

McMillan, D. W. and Chavis, D. M. (1986) 'Sense of community: A definition and theory.' Journal of Community Psychology, 14(1), 6-23.

Macpherson- Parrott, H. and Cherry, E. (2011) 'Using Structured Reading Groups to Facilitate Deep

Murray, R. and Newton, M. (2009) 'Writing retreat as structured intervention: margin or mainstream?' Higher Education Research \& Development, 28(5) pp. 541 - 553

Reay, D. (2003) 'A Risky Business? Mature Working-class Women Students and Access to Higher Education.' Gender and Education, 15(3) pp 301-317

Thomas, L. (2002) 'Student retention in higher education: the role of institutional habitus', Journal of Education Policy, 17(4) pp. 423-442.

Thomas, L. (2012) 'Building student engagement and belonging in Higher Education at a time of change: final report from the What Works? 'Student Retention \& Success programme, London: Paul Hamlyn Foundation, [Online] [Accessed on 10/12/2015] https://www.heacademy.ac.uk/resources/detail/what-works-studentretention/What Works Summary Report

Torbert W. (2006) 'The Practice of Action Inquiry', in Reason P. and Bradbury H., Handbook of Action Research, London: SAGE, 207-217.

Zimmerman B.J. (2002) 'Becoming a Self-Regulated Learner: An Overview' Theory Into Practice, 41(2) pp. $64-70$ 